\title{
The information model of the modern digital production
}

\author{
Alexey Kapitanov ${ }^{1}$, Aleksandra Kozlova ${ }^{1, *}$, and Sergey Tyasto ${ }^{1}$ \\ ${ }^{1}$ MSUT «STANKIN», Department of automated information processing and control systems, 127994 \\ Moscow, Vadkovsky Lane 3A, Russian Federation
}

\begin{abstract}
The article devoted the analysis and research of modern digital production technologies that ensure the transfer of digital design to a physical object. Five target criteria of production digitalization, such as economic efficiency, prototypiny, quality control, interaction, standardization. The article analyzes the dependence of the cost of implementing new tools at the initial stage of transition to digital production and saving of enterprise resources, as well as basic tools of digital production. The concept under consideration is based on integration of mechatronic technologies, computer systems, as well as engineering analysis and adaptation of the work of various equipment and technological equipment with programmatic control. In conclusion, the list of potential advantages, the creation of digital productions at engineering enterprises on the basis of the development and implementation of new critical and high technologies.
\end{abstract}

Digital production technologies are the processes of transition of digital design into a physical object. Digital production is based on the integration of mechatronic technologies, computer systems with computational modeling tools, 3D visualization, reverse engineering and engagement of different equipment and technical devices with software for the purpose of developing the designs of products, technological processes for their manufacturing and operative management of industrial processes.

This concept is illustrated in Fig. 1 depicting continuous digital processing.

Digital production ensures efficient establishment of the sixth technological paradigm, increasing the automation rate, growth of labor productivity, production flexibility, and opportunity for accelerated launching of innovation products into manufacture and change in generations of machines and technology.

\footnotetext{
*Corresponding author: a.kozlova@stankin.ru
} 


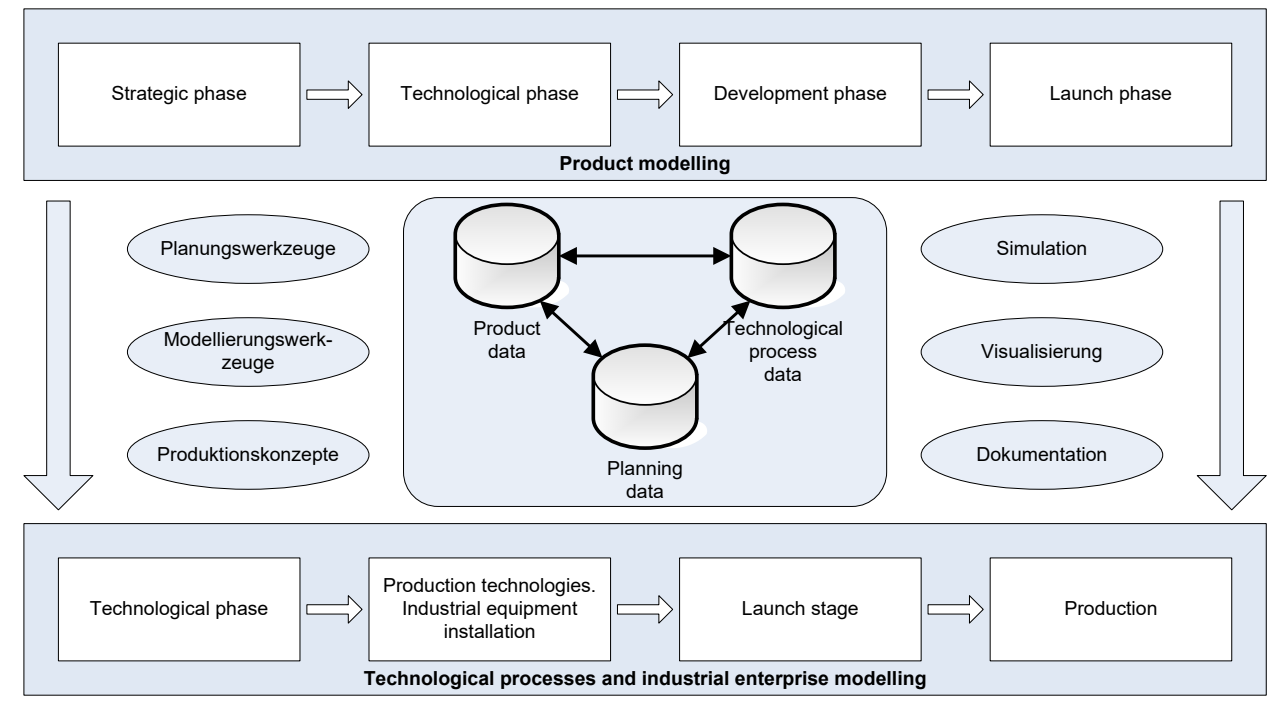

Fig. 1. Concept of a digital industrial enterprise.

There are 5 target criteria of production digitalization.

- Economic efficiency

Maximum synchronization of the entire range of design works, optimization and interdisciplinary approach to cooperation, as well as data updating and correctness allow decreasing the time and cost, hence, increasing the economic efficiency in general.

- $\quad$ Prototyping

Creation of a 3D digital model or a digital twin allows increasing the efficiency and revealing the design issues early on. Assets that generate millions of data points and allow analyzing their value.

- Quality control

The need for production planning is caused by the desire to work with maximum efficiency and minimum expenses while maintaining the required product quality level. Quality control begins with production planning and ends with end product delivery. Throughout all the stages, quality control criteria shall be reflected in the standards of the organization/enterprise with clearly defined requirements.

- Interaction

Integrity, complexity and availability of design data, as well as its unhindered flow in the information space shall provide for integration of all the planning and production participants.

\section{- Standardization}

Process standardization is the initial stage of organization excellence; it includes continuous updating of standards in order to increase their practical efficiency.

Implementation of the above target points requires introduction of new tools at the initial stage of shifting to digital production and leads to additional costs, but in the aftermath these expenses will be compensated. The dependency of resources and expenses saving is shown on the diagram (Figure 2). 


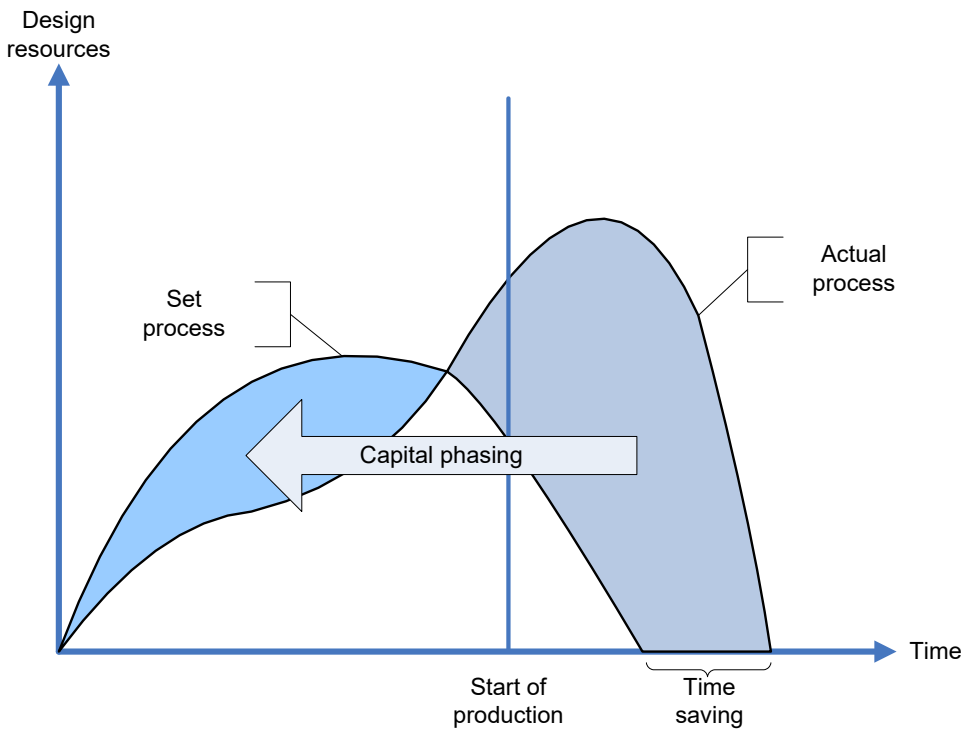

Fig. 2. Resources saving by means of establishment of a DP.

Figure 3 shows digital production tools

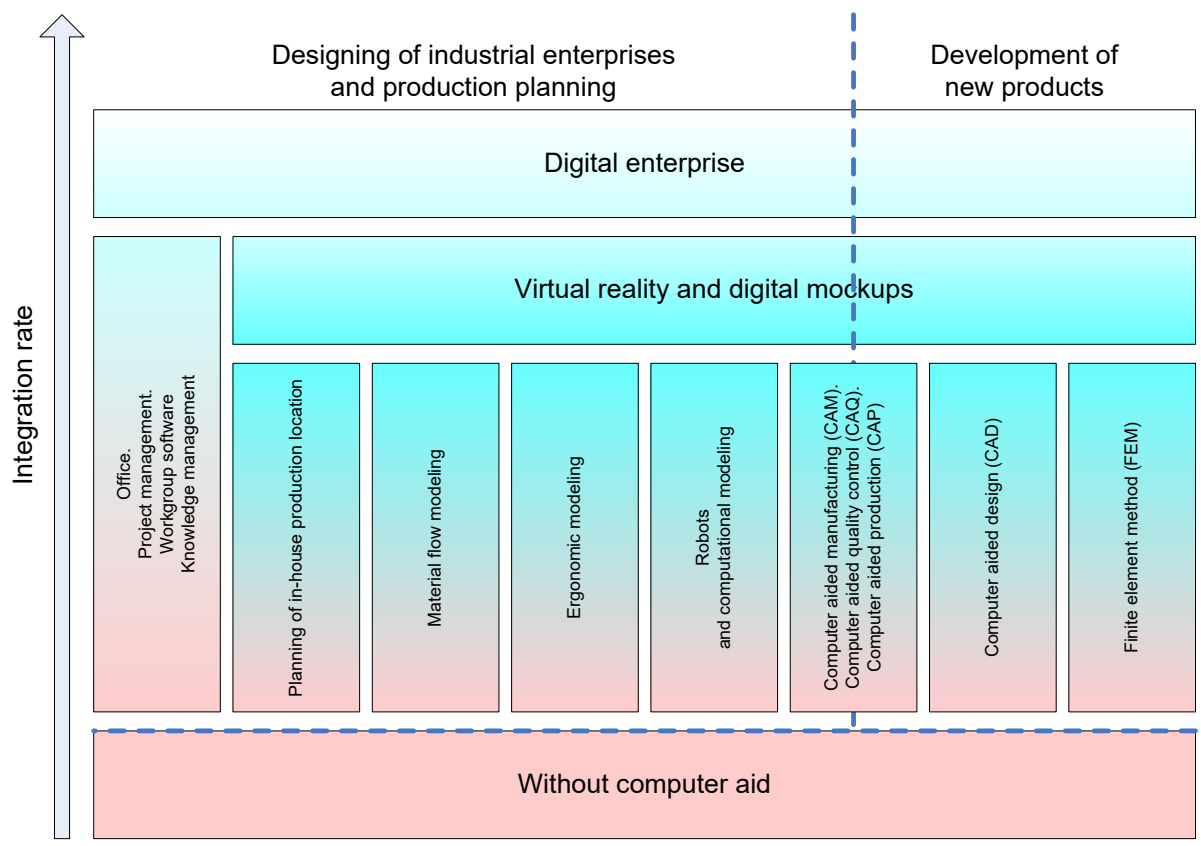

Fig. 3. DP tools.

Innovation design of digital production usually implies the availability of the following computerized components:

- intellectual model(s) forming the digital mockup of the product(s) for information support of all manufacturing processes; 
- information technology of production innovation preparation, which is the basis of the development and engineering of design and optimization of all the production processes at the enterprise;

- highly automated processes allowing launch of new products (innovation products) into manufacture by establishing autonomous production with intellectual models (using artificial intelligence means) and digital processes, including PMISs project management information systems for digital production;

- control systems such as DNC (Direct Numerical Control) are systems controlling a machine group from a single PC with shared memory for software distributed by requests from machines. Such NC units are top grade devices, which ensure arranging of coordinated operation of technological facilities included in the complex, e.g., in FMSs;

- $3 D$ printers or additive machines (if additive technology is engaged) for printing items several meters long;

- mechatronic machines, industrial robots and other PC-operated technical devices complementing popular flexible manufacturing systems, robotic production and intelligent production systems.

\section{Conclusion}

Trends for enterprises of the fifth technological paradigm in top industrial countries point out the necessity of adjusting the list of critical technologies in the Russian Federation. Nowadays, this list is supplemented with digital technologies.

Establishment of digital production at mechanical engineering and instrument engineering factories based on development and introduction of new critical and high technologies and innovation projects provides for the following:

- growth of production volume and production capacity;

- decreased lead time and launching of innovation products and new generation devices into manufacture;

- increase in the domestic market competitiveness;

- increased production flexibility with changes in the product range, stock list and industrial program of innovation product manufacturing by creating a sector (cluster) of digital production enterprises.

The conducted test process works on design and implementation of digital production at the enterprises showed that the following allows validating both the implementation of digital technologies and digital production projects in general: $3 D$ modeling of digital production in a VR room; simulation modeling of equipment loading for feasibility study of product consistency batch launch processes and plant development; and simulation modeling of innovation projects of digital production.

Research in the framework of the grants of the President of the Russian Federation for state support of young scientists МД-6629.2018.9

\section{References}

1. A. A. Kutin, S. S. Ivashin. Technological forecast for digital mechanical engineering enterprises. Innovations magazine, St. Petersburg, No. 8 (214). - p. 9-13. (2016)

2. S. G. Selivanov, A. F. Shaikhulova, S. N. Poezzhalova, A. I. Yakhin, Innovation Design of Digital Production in Mechanical Engineering: guide. - Moscow: Innovatsionnoye Mashinostroyeniye, 264 p. (2016) 
3. S. N. Grigoryev, A. A. Kutin, V. A. Dolgov. Principles for digital production establishment in mechanical engineering. Vestnik MSTU "Stankin”, No. 4 (31), p. 1015 (2014).

4. A. V. Sokolov, A. A. Chulok. Russian Science and Technology Foresight until 2030: Key Features and First Results. Foresight, Vol. 6, No. 1, p. 12-25 (2012).

5. S. N. Grigoryev, A. A. Kutin. Innovation Development of High Technology Processes Based on Integrated CAM Systems. Avtomatizatsiya i Sovremennyie Tekhnologii journal, No. 11, p. 23-29 (2011).

6. S. G. Selivanov, I. A. Krivosheyev, Computer Generated Simulation in Innovational Design of Aircraft Engines, Moscow: Mashinostroyeniye, 330 p. (2010)

7. A.V. Kapitanov, V.G. Mitrofanov, I.S. Omelchenko, O.S. Sirotkin, The Effect of Reliability on the Distribution of a Production Program among Technological Systems at an Engineering Enterprise. Journal of Machinery Manufacture and Reliability 44(7), p.646-649 (2015)

8. A.A. Kutin, The efficiency of GPS in modern mechanical engineering. Technology of mechanical engineering: Review-analytical, scientific-technical and production journal 1, p.56-59 (2012)

9. A. N. Feofanov, Yu. A. Milkina, Planning of multiproduct machine-building enterprise. Economics and management in mechanical engineering 1, p.5-7 (2011)

10. P. Nyhuis, S. Wulf, T. Klemke, B. Benjamin, Integrative factory, technology, and product planning-systemizing the information transfer on the operational level. Production Engineering 4, p.231-237 (2010) 